\title{
Development of a Hardware-in-the-Loop Test Method for Heat Pumps and Chillers
}

\author{
Stutterecker Werner ${ }^{1}$, Schoberer Thomas ${ }^{2}$, Steindl Gernot ${ }^{3}$, \\ ${ }^{1,2}$ Forschung Burgenland, ${ }^{3}$ University of Applied Sciences Burgenland
}

\begin{abstract}
The work presents the development of a Hardwarein-the-Loop test method which enables the solving of integrated energy design problems at a system and concept level for the heat and cold supply of NZEBs based on electrically and thermally driven heat pumps and chillers. The main result is the realization of a test rig consisting of hardware (e.g. thermally driven chiller, or heat pump etc.), of software (e.g. LabView, TRNSYS) and the interface for the interaction of hardware and software.
\end{abstract}

Keywords - Heat pumps \& Chillers, Building Simulation, Hardware-in-the-Loop test method

\section{INTRODUCTION}

In building services, the supply of a building with heat and cold based on the technologies involving heat pump and chillers plays a major role. In the last years due to a better insulation standard of the building envelope, the heating demand was reduced in residential buildings. This is the case for new buildings but also for the retrofitting of old buildings. In relation to the heating demand, user induced demands like the one for hot water production or plug-loads are rising and getting more important, especially for nearly zero energy buildings [1],[2]. In non-residential buildings like in office buildings the cooling loads are rising on the one hand due to higher internal loads caused by a higher use of information technologies and on the other hand due to building physical and architectural compromises (like glass facades) [3].

In many research scenarios for the future energy supply of buildings heat pumps and chillers are in the focus. In Streicher, et al. [4], for example, the electrical heat pump together with solar thermal energy is the future supply scenario in the building sector. But also thermally driven heat pumps (for example gas fired ones) are treated as the successor of condensing boilers [5].

Decreasing heating energy demand and at the same time rising cooling energy demand specifically require devices and systems, which can cover both heating and cooling loads. This is an argument for the heat pump and chiller technology, since there are both heat pumps and chillers available on the market which can heat and cool in one device. However, there is a need for research, especially at the system and concept level [5], [6].

\section{OBJECTIVES}

The aim of the project 'energy4buildings' is the development of an innovative method which enables the solving of integrated energy design problems at a system and concept level for the heat and cold supply of nearly zero energy buildings based on electrically and thermally driven heat pumps and chillers. Therefore infrastructure, competence and know-how have to be built up. The following research questions will be addressed by the project:

- How can electrically and thermally driven heat pumps and chillers be integrated in the energy concept of a building (single family house, apartment houses, small offices) in an energy efficient way?

- How can real performance conditions of heat pumps and chillers at a system and concept level (meaning in combination with other systems like solar energy and concepts like thermal and electrical load management) be simulated at a Hardwarein-the-Loop test rig?

- How must control strategies be further developed in order to fulfil todays and future requirements of nearly zero energy buildings including the user and the weather?

The above mentioned topics have to be considered especially in the context of the energy performance of buildings directive [1], which demands that all new buildings are built as nearly zero energy buildings and that incentives are created to support the refurbishment to nearly zero energy buildings until 2020. The aim of the project partner AEE INTEC is to adopt an existing test rig for solar thermal energy in order to answer integrated questions about the combination of heat pumps and chillers with solar thermal energy. The project 'energy4buildings' is a 5-year project which began in May 2013 and will be evaluated after two years. The project comprises among others the following work packages construction of the test rig (hardware), Building and Building Services Simulation (software), integration of the hardware and the software to an integrated test rig (interface).

\section{MethodologIES}

In order to give answers to the above-stated research questions, the development of an innovative method where integrated problems about heating and cooling with electrically and thermally driven heat pumps and chillers as building services can be solved at a system and concept level is necessary. This method consists of three parts: testing of hardware in the laboratory, building and building services simulation, and interaction of these two parts in real time. The application of this method, respectively, the combination of the above mentioned three parts will be realized in the development of an integrated energy design test rig for heating and cooling with a focus on electrically and thermally driven heat pumps and chillers. 
The developed integrated test rig enables to answer questions, especially about part load behaviour and the performance of all energy relevant components at a system and concept level. Fig. 1 displays the main idea of the integrated energy design test rig. The figure shows the interface between the hardware and the simulation software like TRNSYS.

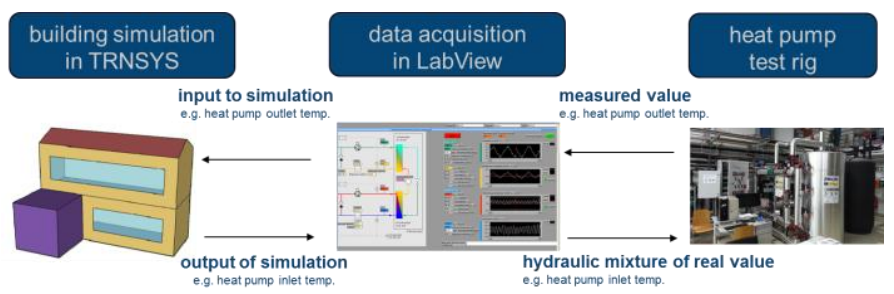

Fig. 1. The Hardware-in-the-Loop principle of the test rig for integrated heating and cooling.

Therefore, an interface between LabView and TRNSYS [7] has to be implemented in order to ensure a reliable communication and synchronization between the two software programs. It will be possible to run the control and simulation software on different computers as well. This will prevent performance insufficiency, which can occur if both tasks are executed on one PC. After TRNSYS has communicated its calculation results of the actual time step, e.g. the return temperature of the chilled ceiling, the calculated return temperature has to be hydraulically mixed. Therefore, the interface has a computational aspect (the communication between the two software programs) and a hydraulic aspect (for the mixture of the right temperatures entering the hardware) (see Fig. 1).

In order to increase the accuracy of the integrated energy design test rig, the simulation models have to be validated. For the validation, mobile monitoring equipment will be purchased and field monitoring will be conducted in suitable building types like single family houses, apartment houses and small offices. The monitoring equipment is planned to comprise, for example, thermal and electrical load measurements, hygrothermal room parameters and weather conditions like global radiation and outdoor air temperature. Additionally, monitoring results from past projects like the monitoring results of an apartment house with semi-central ventilation with decentralized heat pumps and PV-modules on the roof (Stutterecker and Blümel, 2012) will be used for validation. Despite the use of monitoring results, well validated CFD models will also be used for the validation of single components like a chilled ceiling.

\section{RESULTS}

\section{A. The Hardware}

Fig. 2 shows the existing heat pump test rig at the University of Applied Sciences Burgenland, which will be adjusted to an integrated test rig for thermally and electrically driven heat pumps and chillers with an interface for building and building services simulation. In the first months of the project, the main focus was on the construction of the hot water cycle, which will drive thermal heat pumps or chillers (WP Construction of the test rig). The hydraulic planning and the planning of the measurement equipment for the test rig were finished and first test runs of the components were successfully completed. The first test runs were done with a thermal adsorption chiller ( $8 \mathrm{~kW}$ nominal cooling capacity) in order to test all hardware components especially of the hot water cycle. Later on, an electrical heat pump with a heating capacity of $13 \mathrm{~kW}$ will be tested. However the total finished test rig is dimensioned to test devices with a condenser power of up to $100 \mathrm{~kW}$. The total hardware of the test rig consists of 3 cycles: the evaporator cycle for the interface with the evaporator of a heat pump or chiller, the condenser cycle for the interface with the condenser of a heat pump or chiller, and of a hot water cycle for thermally driven machines.

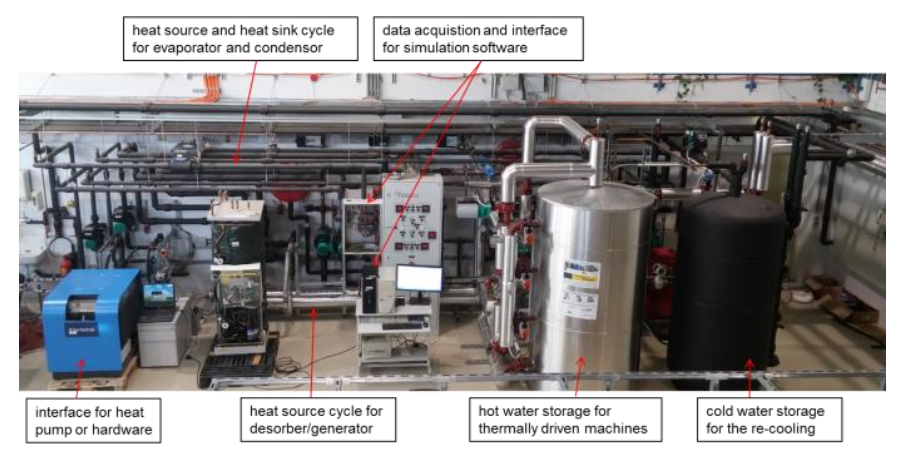

Fig. 2. The test-rig for electrically/thermally driven heat pumps and chillers.

The hydraulic concept of the hot water cycle will be integrated in the existing heat pump test rig (Fig. 3). The data acquisition was realized with LabView [8]. The main measurement points are temperature and mass flow rate in order to balance the evaporator cycle, the condenser cycle and the hot water cycle.

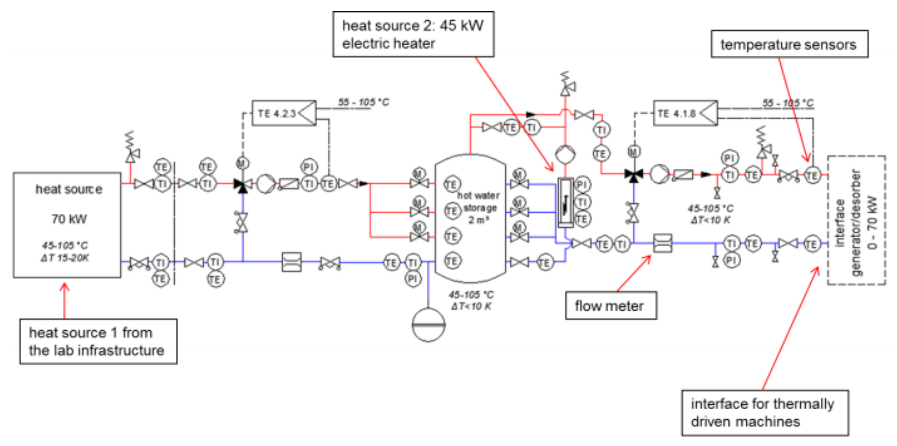

Fig. 3. The hydraulic scheme of the hot water cycle.

For the temperature measurement PT 100 sensors are used. Before they are implemented, the whole measurement chain is calibrated against a reference temperature sensor, which itself has a calibration certificate of the Deutscher Kalibrierdienst. The mass flow rate is measured with a magnetic inductive sensor. In order to calculate the COP, the electrical power consumption is also measured. With this measurement points the heat pump or chiller can be fully balanced. 


\section{B. The Software}

The work package Building and Building Services Simulation is important in order to realize the Hardware-inthe-Loop test rig. The first focus of this work package will be on the validation of the floor heating and chilled ceiling models of TRNSYS (type 56). The validation will be done in the first step with the CFD code ANSYS FLUENT [9]. Once the floor heating and chilled ceiling model is validated (or if necessary further developed), control strategies of heat pumps and chillers in combination with thermal storage masses of the floor or ceiling can be analysed. In the following chapter, software comparison will be made between TRNSYS (Version 17.01.0028) and the CFD code ANSYS FLUENT (Release Version 14.5). The FLUENT simulations of the ceiling cooling system were made by Heschl [10] and the simulations of the floor heating system by Klanatsky [11].

\section{Ceiling Cooling System}

Therefore, a ceiling cooling system was defined and the boundary and input parameter were harmonized between TRNSYS and ANSYS FLUENT in order to get comparable results. Only a small area $\left(2 \mathrm{~m}^{2}\right)$ was chosen in order to minimize the grid generation effort in ANSYS FLUENT. The pipe specifications and the ceiling layer specifications can be found in Table 1 and Table 2.

\section{TABLE 1}

PIPE SPECIFICATIONS - CEILING COOLING SYSTEM

\begin{tabular}{lrl}
\hline Type & Value & Unit \\
\hline Spacing & 150 & $\mathrm{~mm}$ \\
Outside diameter & 14 & $\mathrm{~mm}$ \\
Wall thickness & 2 & $\mathrm{~mm}$ \\
Length & 13.33 & $\mathrm{~m}$ \\
Wall conductivity & 0.792 & $\mathrm{~kJ} /(\mathrm{hr} . \mathrm{m} . \mathrm{K})$ \\
\hline
\end{tabular}

All parts of the model (walls, ambience etc.) were initialized with a temperature of $26^{\circ} \mathrm{C}$. The room temperature was kept constant during the whole simulation at $26^{\circ} \mathrm{C}$. The convective heat transfer coefficient on the inside (ceiling side with ferro-concrete) and on the outside (floor side with screed) were held constant during the whole simulation (see Table 3).
TABLE 3

SYSTEM AND SOFTWARE SPECIFICATIONS - CEILING COOLING SYSTEM

\begin{tabular}{lrr}
\hline Type & Value & Unit \\
\hline Boundary temperatures & 26 & ${ }^{\circ} \mathrm{C}$ \\
$\quad$ Area & 2 & $\mathrm{~m}^{2}$ \\
$\quad$ Convective heat transfer coefficient: & 10.8 & $\mathrm{~W} /\left(\mathrm{m}^{2} . \mathrm{K}\right)$ \\
$\quad$ inside & 6.5 & $\mathrm{~W} /\left(\mathrm{m}^{2} . \mathrm{K}\right)$ \\
$\quad$ outside & & \\
$\quad$ Fluid (if control is on): & 15 & $\mathrm{~kg} /\left(\mathrm{m}^{2} \cdot \mathrm{hr}\right)$ \\
$\quad$ mass flow rate & 17 & ${ }^{\circ} \mathrm{C}$ \\
$\quad$ inlet temperature & & $\mathrm{min}$ \\
$\quad$ ANSYS FLUENT specific inputs: & 1 & - \\
$\quad$ Time step size & 20 & $\mathrm{~min}$ \\
$\quad$ Iterations per time step & & $\mathrm{hr}$ \\
$\quad$ TRNSYS specific inputs: & 1 & 0.2 \\
$\quad$ Time step & &
\end{tabular}

For the first comparison, a consecutive series of three step functions was applied to the system ( $24 \mathrm{hrs}$ cooling on -12 hrs cooling off -12 hrs cooling on). In the first step the fluid entered the system with a temperature of $17{ }^{\circ} \mathrm{C}$ and a mass flow rate of $15 \mathrm{~kg} / \mathrm{hr}$. The duration of the first step was 24 hours. The simulation results of the first step are displayed in the following figures. The stair-step effect in these figures results from the built-in transfer functions for walls in TRNSYS. As mentioned in Table 3, the time base for the transfer function was 0.2 hour. In Fig. 4 the surface temperatures on the ceiling (inside) and on the floor (outside) are shown. The maximum difference between the surface temperatures on the inside was $0.14 \mathrm{~K}$ which was observed after 24 hours. The maximum difference of the outside surface temperatures was $0.05 \mathrm{~K}$ again after 24 hours, when the temperatures were approaching a stationary status.

The cooling performance of the activated wall is shown in Fig. 4 (bottom subplot). The maximum difference between the two inside walls was $1.5 \mathrm{~W} /\left(\mathrm{m}^{2} . \mathrm{K}\right)$ whereas the maximum difference on the two outside walls was $0.3 \mathrm{~W} /\left(\mathrm{m}^{2} . \mathrm{K}\right)$. These maximum differences occurred after 24 hours.

In the second step, the mass flow rate of the active layer was set to $0 \mathrm{~kg} / \mathrm{hr}$ after 24 hours for the consecutive 12 hours (see Fig. 5). By trend, the difference between TRNSYS and ANSYS FLUENT at the end of 1st step is now decreasing during the simulation time of the 2 nd step.

TABLE 2

CEILING LAYER SPECIFICATIONS (FROM INSIDE TO OUTSIDE) - CEILING COOLING SYSTEM

\begin{tabular}{lrrrr}
\hline Type & $\begin{array}{r}\text { Thickness } \\
{[\mathrm{mm}]}\end{array}$ & $\begin{array}{r}\text { Conductivity } \\
{[\mathrm{W} /(\mathrm{m} . \mathrm{K})]}\end{array}$ & $\begin{array}{r}\text { Density } \\
{\left[\mathrm{kg} / \mathrm{m}^{3}\right]}\end{array}$ & $\begin{array}{r}\text { Specific heat } \\
{[\mathrm{kJ} /(\mathrm{kg} . \mathrm{K})]}\end{array}$ \\
\hline Ferro-concrete & 45 & 2.3 & 2400 & 1.08 \\
Active layer & - & - & - & - \\
Ferro-concrete & 155 & 2.3 & 2400 & 1.08 \\
Filling & 10 & 2.0 & 2400 & 1.00 \\
Insulation & 15 & 0.04 & 58 & 1.45 \\
Screed & 50 & 1.4 & 2000 & 1.08 \\
\hline
\end{tabular}



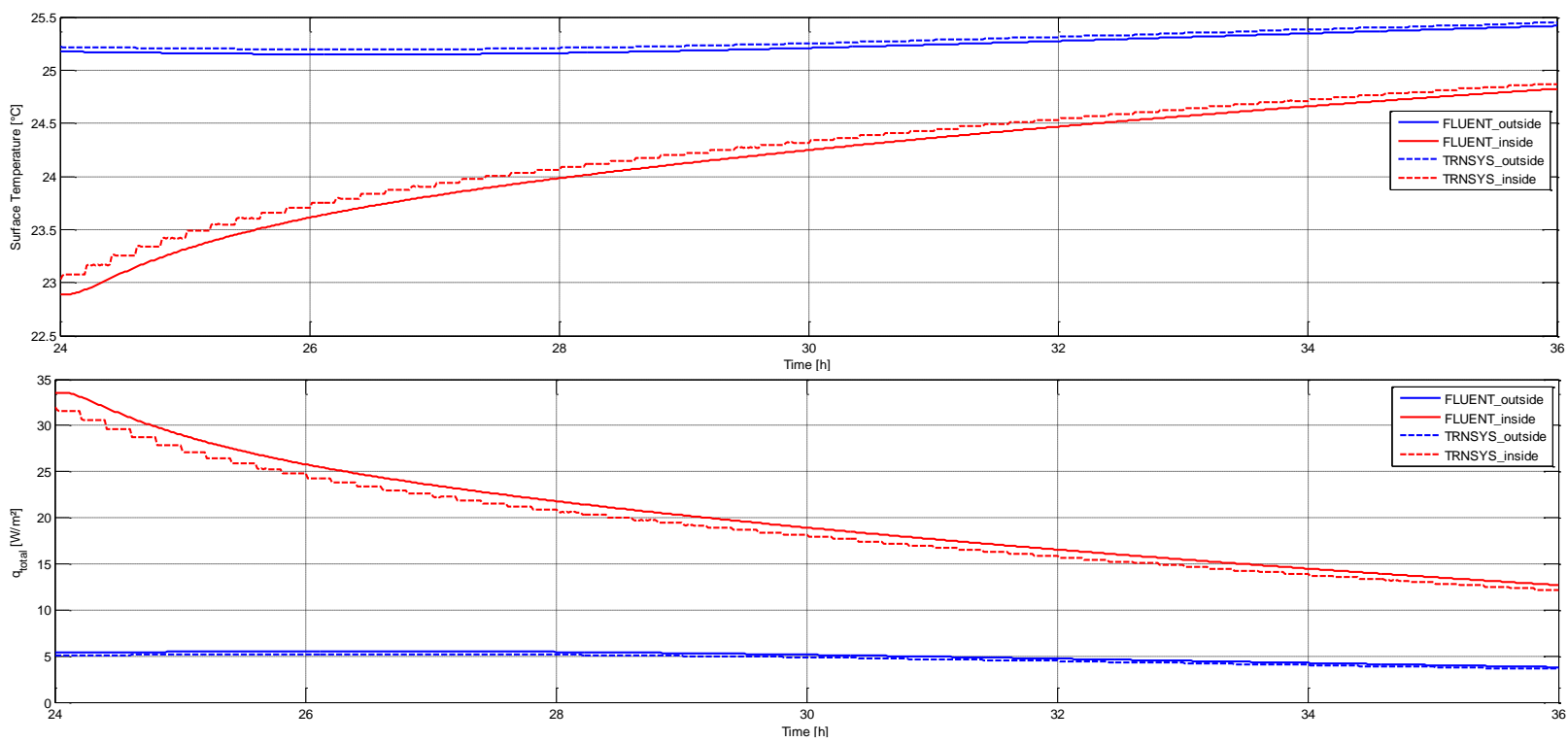

Fig. 4. Top: surface temperatures, bottom: cooling performance -2 nd step.

\section{Floor Heating System}

In the second comparison, a floor heating system was simulated in TRNSYS and ANSYS FLUENT. The difference in the second comparison is that a much shorter on-off-profile of the mass flow rate of the active layer was applied to a floor heating system (see Fig. 5). The profile varies over one week and an on-phase only lasts a few hours. The profile could be a heating profile of a building. The pipe, layer and system specifications of the comparison are shown in Table 4 to Table 6.

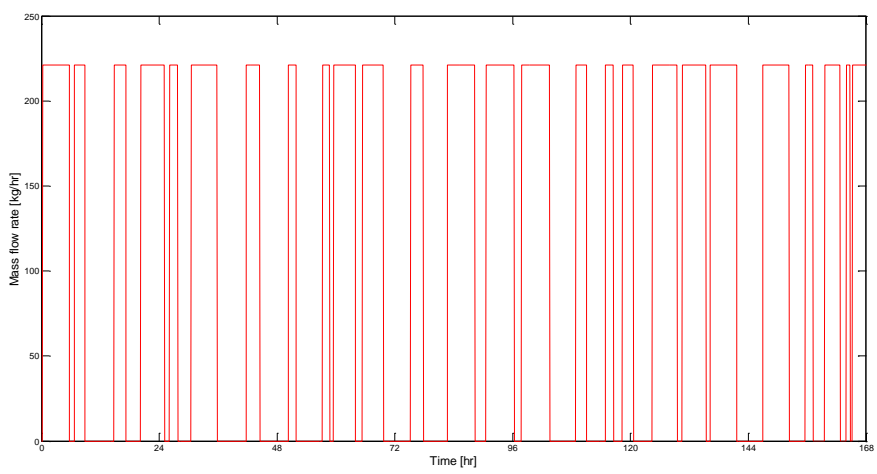

Fig. 5. On-off-profile of the mass flow rate of the active layer, $221 \mathrm{~kg} / \mathrm{hr}$.
TABLE 4

PIPE SPECIFICATIONS - FLOOR HEATING

\begin{tabular}{lrl}
\hline Type & Value & Unit \\
\hline Spacing & 150 & $\mathrm{~mm}$ \\
Outside diameter & 17.6 & $\mathrm{~mm}$ \\
Wall thickness & 2.3 & $\mathrm{~mm}$ \\
Length & 153.6 & $\mathrm{~m}$ \\
Wall conductivity & 1.26 & $\mathrm{~kJ} /(\mathrm{hr} . \mathrm{m} . \mathrm{K})$ \\
\hline
\end{tabular}

TABLE 6

SYSTEM AND SOFTWARE SPECIFICATIONS - FLOOR HEATING

\begin{tabular}{lrr}
\hline Type & Value & Unit \\
\hline Boundary temperatures & 26 & ${ }^{\circ} \mathrm{C}$ \\
$\quad$ Area & 2 & $\mathrm{~m}^{2}$ \\
$\quad$ Convective heat transfer coefficient: & 10.8 & $\mathrm{~W} /\left(\mathrm{m}^{2} . \mathrm{K}\right)$ \\
$\quad$ inside & 6.5 & $\mathrm{~W} /\left(\mathrm{m}^{2} . \mathrm{K}\right)$ \\
$\quad$ outside & & \\
$\quad$ Fluid (if control is on): & 15 & $\mathrm{~kg} /\left(\mathrm{m}^{2} . \mathrm{hr}\right)$ \\
$\quad$ mass flow rate & 17 & ${ }^{\circ} \mathrm{C}$ \\
$\quad$ inlet temperature & & $\mathrm{min}$ \\
$\quad$ ANSYS FLUENT specific inputs: & 1 & - \\
$\quad$ Time step size & 20 & $\mathrm{~min}$ \\
$\quad$ Iterations per time step & & $\mathrm{hr}$ \\
$\quad$ TRNSYS specific inputs: & 1 & \\
$\quad$ Time step & 0.2 & \\
$\quad$ Time base & &
\end{tabular}

Fig. 6 shows a comparison between the inlet temperature of the active layer in TRNSYS and ANSYS FLUENT. While the inlet temperature in TRNSYS was $32^{\circ} \mathrm{C}$ all the time, the inlet temperature in FLUENT was only $32{ }^{\circ} \mathrm{C}$ when the mass flow rate of $221 \mathrm{~kg} / \mathrm{hr}$ was applied.

TABLE 5

LAYER SPECIFICATIONS (FROM INSIDE TO OUTSIDE) - FLOOR HEATING

\begin{tabular}{lrrrr}
\hline Type & $\begin{array}{r}\text { Thickness } \\
{[\mathrm{mm}]}\end{array}$ & $\begin{array}{r}\text { Conductivity } \\
{[\mathrm{W} /(\mathrm{m} . \mathrm{K})]}\end{array}$ & $\begin{array}{r}\text { Density } \\
{\left[\mathrm{kg} / \mathrm{m}^{3}\right]}\end{array}$ & $\begin{array}{r}\text { Specific heat } \\
{[\mathrm{kJ} /(\mathrm{kg} . \mathrm{K})]}\end{array}$ \\
\hline Floor cover 1 & 4 & 0.200 & 800 & 800 \\
Floor cover 2 & 7 & 0.130 & 1000 & 2.50 \\
Glue & 1 & 0.180 & 2200 & 1.26 \\
Screed & 54 & 1.400 & & 1.13 \\
Active Layer & & & 15 & \\
Screed & 14 & 0.040 & 40 & 1.40 \\
Sound insulation & 30 & 0.025 & 2000 & 1.40 \\
Insulation & 52 & 0.800 & 2400 & 1.20 \\
Split & 10 & 2.300 & 1800 & 1.13 \\
Ferro-concrete & 200 & 0.800 & & 1.13 \\
Render & 10 & & \\
\hline
\end{tabular}




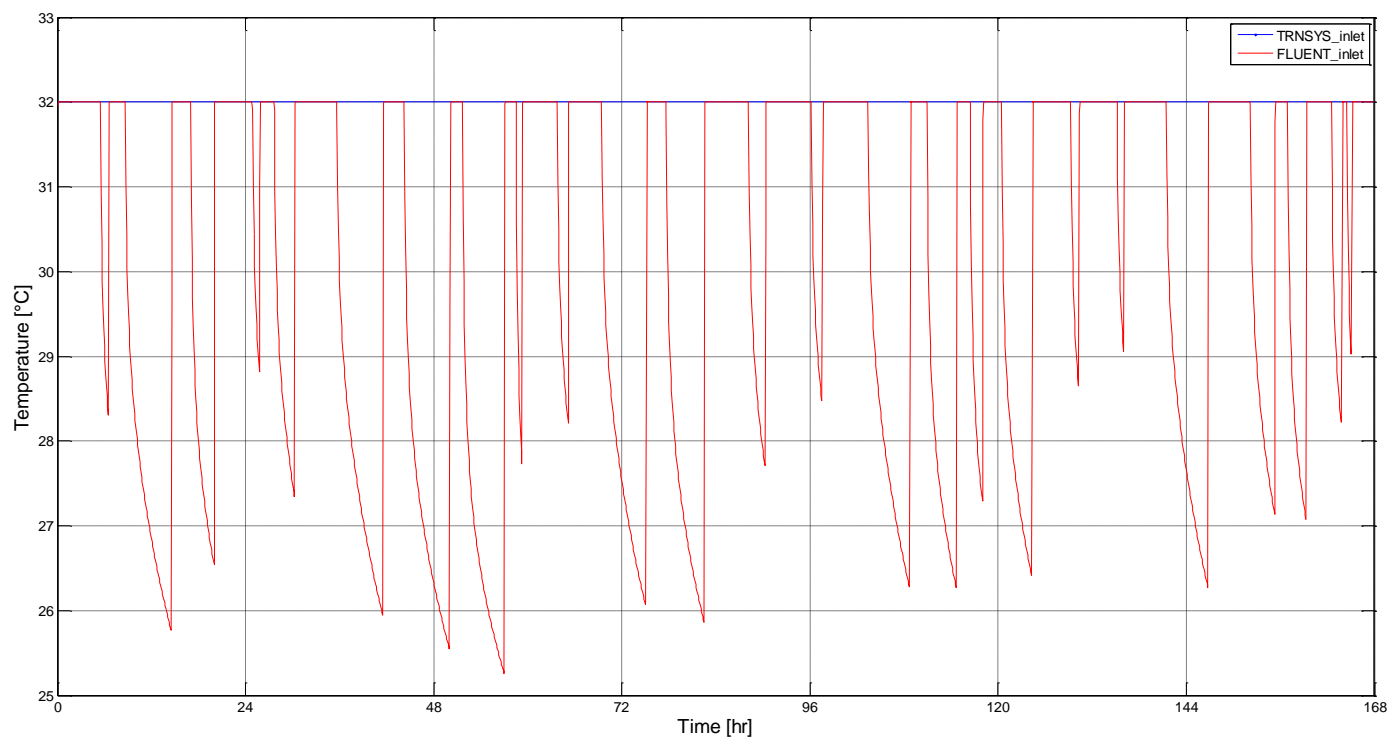

Fig. 6. The inlet temperature to the active layer.

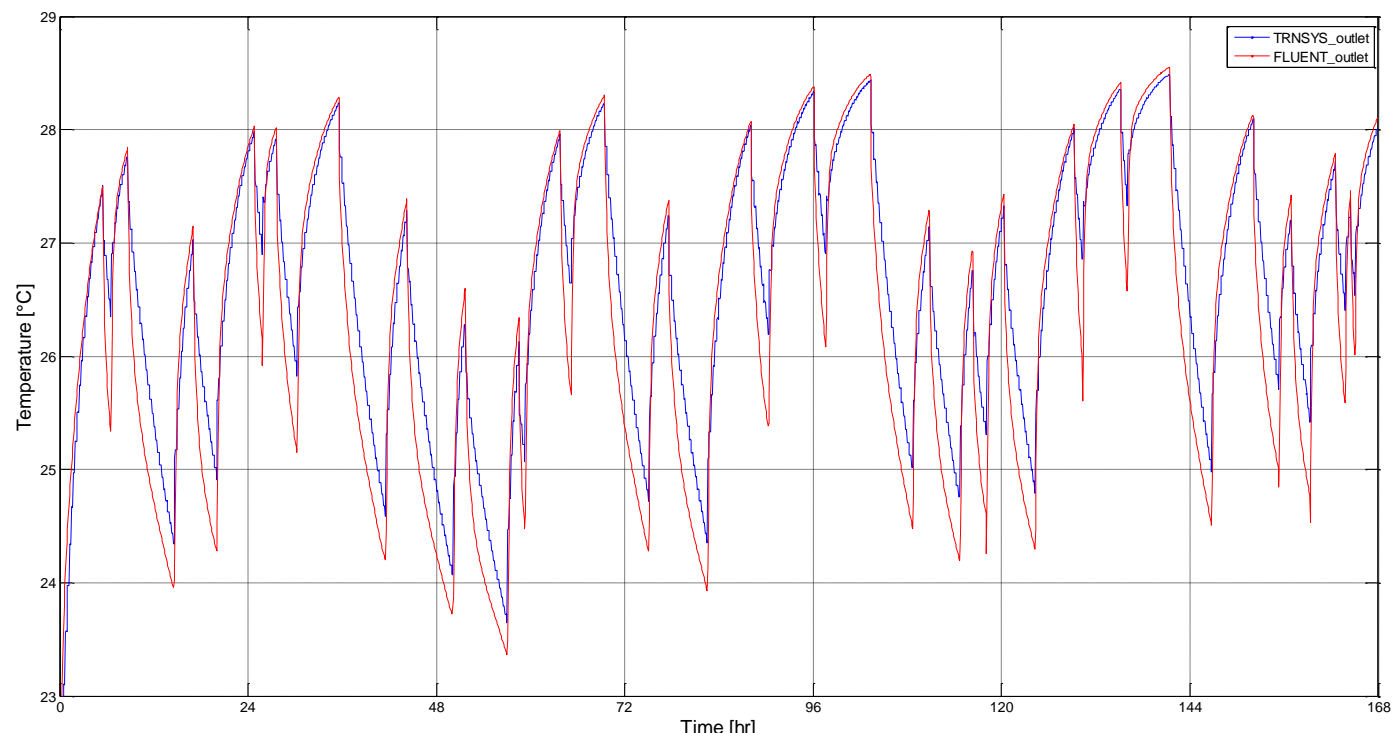

Fig. 7. The outlet temperature of the active layer.

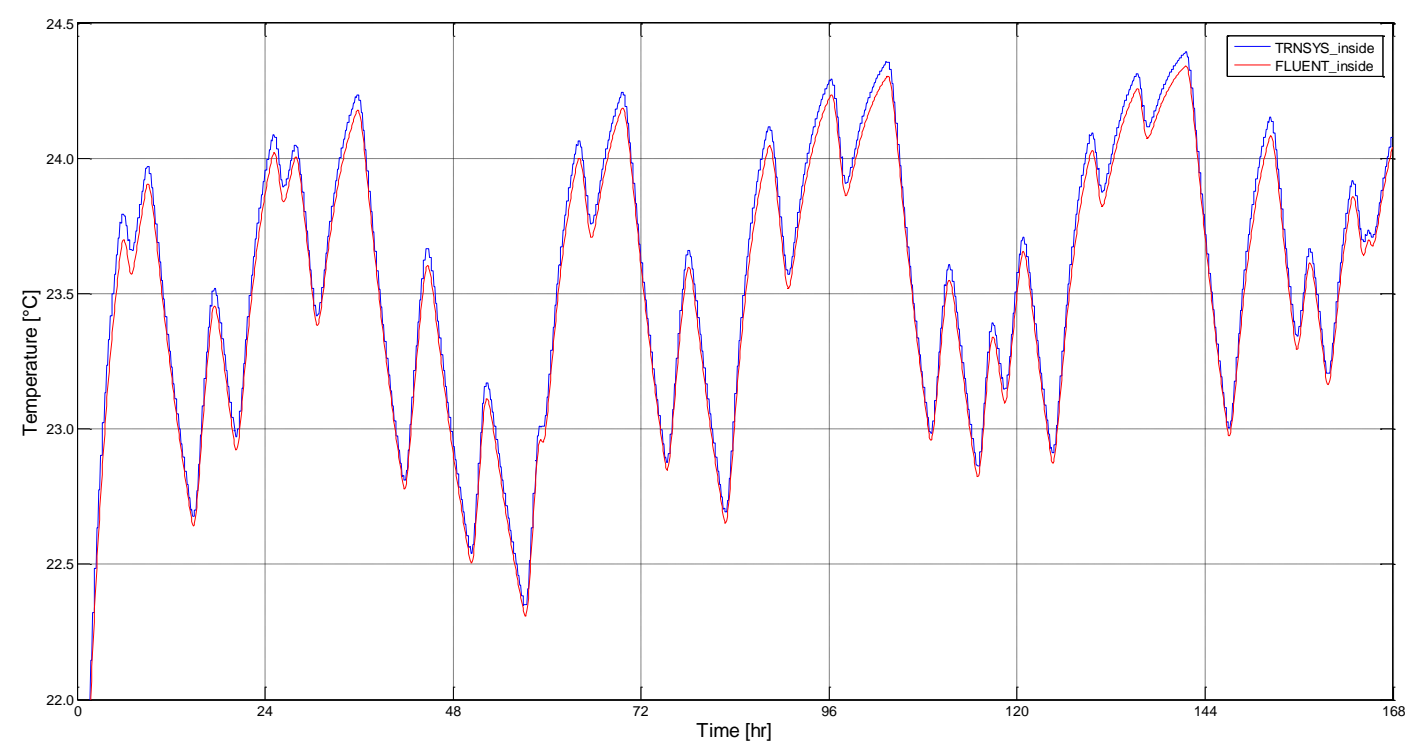

Fig. 8. Inside surface temperature of the activated wall. 


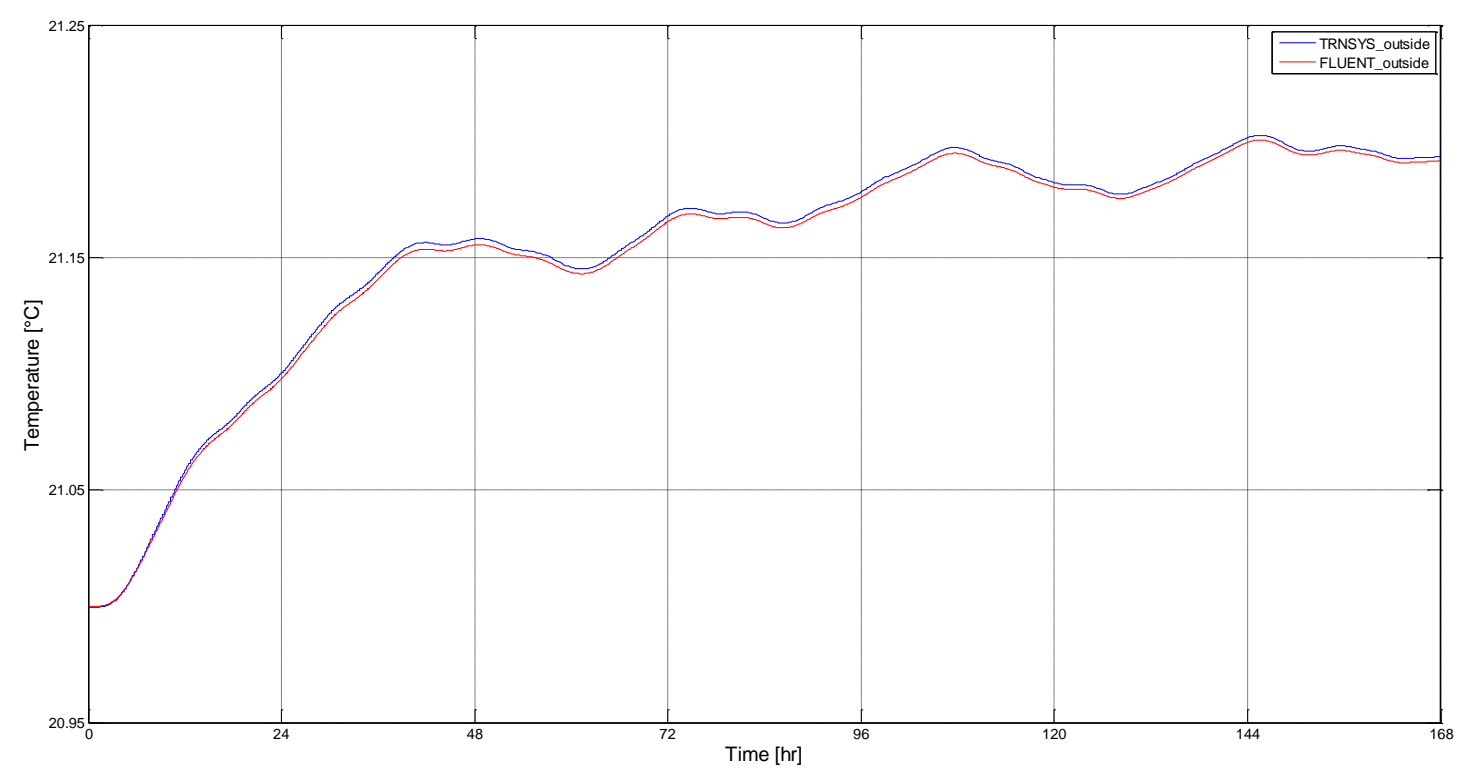

Fig. 9. Outside surface temperature of the activated wall.

This is due to the fact that in FLUENT the temperature of the water decreased due to heat conduction during the offphase (change of the internal energy of the water). This is the reason for the negative peaks during the off-phases in the FLUENT simulation.

In Fig. 7 the outlet temperature of the active layer is compared. During the on-phases TRNSYS seems to slightly underestimate the outlet temperature, but the difference is lower than $0.1 \mathrm{~K}$. However, during the off-phases TRNSYS calculates a higher temperature compared to FLUENT with differences lower than $1 \mathrm{~K}$. The mean value over the whole week was $26.63{ }^{\circ} \mathrm{C}$ for TRNSYS and $26.37^{\circ} \mathrm{C}$ for FLUENT.

The inside surface temperatures of the TRNSYS calculation are only slightly higher than the FLUENT temperatures over the whole profile (see Fig. 8). The magnitude of the difference is lower than $0.1 \mathrm{~K}$. The mean value of the TRNSYS simulation was $23.55^{\circ} \mathrm{C}$, while the mean value in FLUENT was $23.50{ }^{\circ} \mathrm{C}$. An even minor difference can be observed at the outside surface temperature, as shown in Fig. 9. In this case, the difference was in the magnitude of $0.01 \mathrm{~K}$. Again, the TRNSYS calculation was negligibly higher compared to FLUENT, as mentioned above.

\section{Results of the Software Comparison}

The analysis and the comparison of the software TRNSYS and ANSYS FLUENT revealed minor differences in the simulation of the surface temperature and the emitted cooling and heating power of an activated wall. Under these conditions, the comfort parameters according to ÖNORM EN ISO 7730 [12], which are influenced by different room air and mean radiant temperatures, are not expected to differ significantly. However, it has to be stated that the room temperature was held constant, the convective heat transfer coefficient was held constant and no internal or external loads were applied in both test cases (ceiling cooling and floor heating system). This means that further research must be done where specifically internal and external loads are taken into consideration as well. The differences in the simulation results between TRNSYS and FLUENT might increase with an increasing complexity of the modelled case, and of course if 3-dimensional influences are considered. A highly 3Ddiscretisized room for example could lead to a significantly different evaluation of the comfort parameters as well. Therefore, when energy systems for buildings or even whole building concepts are designed these effects must be taken into account.

The computational time differs between TRNSYS and FLUENT. Since TRNSYS can be considered as fast (compared to FLUENT), TRNSYS shows a good compatibility for Hardware-in-the-Loop applications, where calculations should be made at least at real-time speed (or faster).

\section{The Hardware-in-the-Loop test rig}

The aim of the HIL test rig is to test hardware like a heat pump under the environment of simulation software like TRNSYS. Since the hardware and the simulation software will interact bi-directionally, dynamic and transient phenomena like the part load behaviour of heat pumps, control strategies or thermal storage effects of building masses can be analysed. Additionally, integrated energy analyses can be done on a system and concept level, considering a certain building, building services, the user and climatic and weather influences. Fig. 10 shows a simulation example of a small office in TRNSYS with the newly developed interface type for LabView. The interface type enables that data can be written to and read from LabView. The type can be easily connected to other standard types in TRNSYS and the number of input and output parameters can be set in the pro forma of the type.

The communication between TRNSYS and LabView works via TCP-sockets, in order to ensure a reliable communication and synchronization between the two software programs. The communication structure of LabView is shown in Fig. 11. In the first step, the data is read from TRNSYS, then 
measurement and control operations can be processed in LabView, and finally the data is written to TRNSYS.

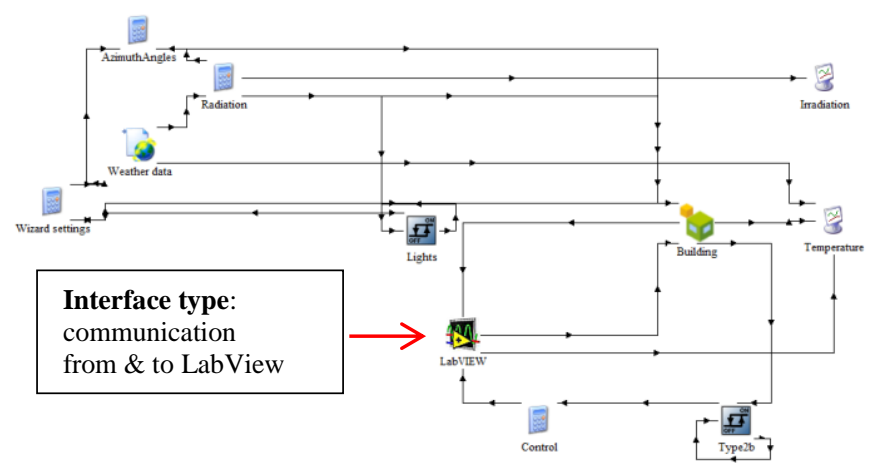

Fig. 10. Simulation example of a small office building in TRNSYS with the new developed interface type.

During the data processing in LabView, TRNSYS is set to a stand-by mode. Only if all output values are available in LabView, the data is written to TRNSYS and the next time step can be processed in TRNSYS. To put it in other words, TRNSYS has to wait for LabView for the calculation of the next time step. This supports the idea of the HIL test rig, because a simulated value of TRNSYS e.g. an outlet temperature of an active layer has to be hydraulically mixed to a real value with the help of LabView. If a certain tolerance between the simulated and real value is fulfilled, the next simulation can be done.

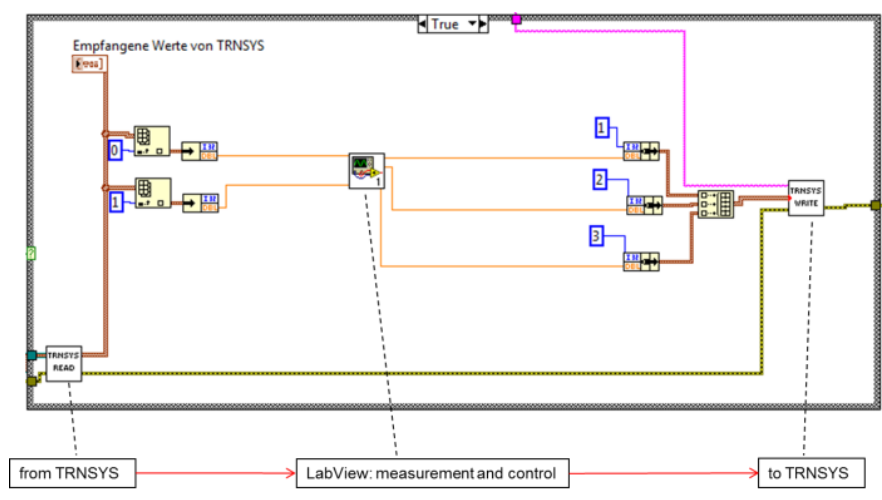

Fig. 11. Communication structure in LabView: read from TRNSYS $\rightarrow$ measurement \& control in LabView $\rightarrow$ write to TRNSYS.

The results of a simulation example are displayed in Fig. 12. In this case, a small office building was modelled in TRNSYS 17 and the new communication type was implemented to the model as mentioned above. In order to test the communication, an absorption chiller was modelled in LabView instead of an interactive measurement of a real chiller. The cooling power of the chiller was modelled with the help of a curve fit as a function of the chilled water return temperature, the hot water and the cooling water inlet temperature. In Fig. 12 the chilled water outlet temperature (from LabView), the chilled water return temperature (calculated by TRNSYS) and the cooling power (from LabView) are displayed.
Fig. 12 shows the working interaction between TRNSYS and LabView and the dynamic behaviour of an active layer and the chiller can be observed. Since this paper describes a newly developed method, an interpretation of the values will be done in future work with a real sorption chiller.

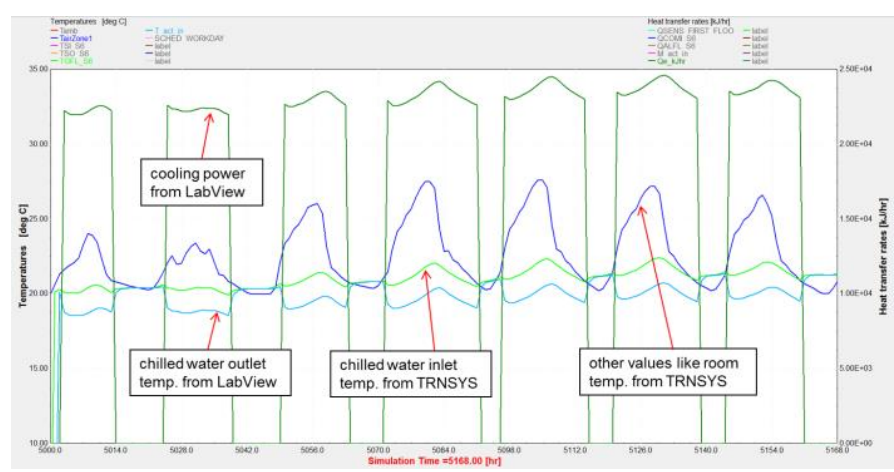

Fig. 12: TRNSYS Simulation example of a small office building (chilled water outlet temperature from LabView, the chilled water return temperature calculated by TRNSYS, the cooling power from LabView, the indoor air temperature).

\section{V.DISCUSSION}

This newly developed method, which allows the testing of electrically and thermally driven heat pumps and chillers under a Hardware-in-the-Loop environment, can be used to analyse heating and cooling concepts on a system and concept level. This will be more and more important, especially due to national and European regulations like the Energy Performance of Buildings Directive [1] or the Energy Efficiency Directive [13]. In order to enforce the use of renewable energy, heat pumps and chillers must not only be efficient by themselves, but also the integration of these machines into the heating or cooling system, or even the integration into the whole building concept must be done in the most energy efficient way. With the help of this developed method, different electrically and thermally driven heat pumps and chillers can be tested on the test rig, while these machines are embedded into a building simulation environment. Within this building simulation environment different building concepts can be easily changed and the effect on the machine can be directly measured. Also on a system level the effect on e.g. a heat pump of different heat delivery systems like a floor heating or radiators can be evaluated and measured on the test rig. Furthermore, this method helps to implement and evaluate different control strategies, while the control is modelled in TRNSYS, but the effect on the machine is measured in reality.

Within this Hardware-in-the-Loop environment dynamic and transient effects, like they occur e.g. in chilled ceilings or other active building layers, can be taken into consideration as well, especially when thermal comfort is evaluated. These dynamic effects are also important, when heating or cooling machines are combined with a PV-system. Then control strategies (e.g. predictive control) must be specifically elaborated in order to ensure a Nearly Zero Energy Building. 
The next steps in the development of the method of using a Hardware-in-the-Loop simulation in the field of building services and technologies are to implement the mentioned simulation example of a small office building fully at the test rig. This means that instead of a curve-fit model in LabView, a real machine will be measured. For this simulation, an example of a small office building an adsorption chiller with a nominal cooling power of $8 \mathrm{~kW}$ will be used. After the test with a real machine, further building models must be developed and validated.

\section{CONCLUSIONS}

For the integration of electrically and thermally driven heat pumps and chillers to nearly zero energy buildings in the most energy efficient way (system and building concept level), new test methods must be developed, which allow analyzing the degree of integration. The newly developed method will follow a Hardware-in-the-Loop principle, consisting of the three parts testing the hardware in the laboratory, building and building services simulation, and interaction of these two previous parts in real time. The application of this method, respectively, the combination of the above mentioned three parts will be realized in the development of an integrated energy design test rig. In order to increase the accuracy of the integrated energy design test rig, the responding simulation models have to be validated via field measurements and via already validated CFD models. After successful validation, the test rig can be used to research questions about an integrated energy design of heat pump and chiller based nearly zero energy building concepts. Finally, the analysis of the part load behaviour and the performance of all energy relevant components at a system and concept level can be done.

The simulation of a ceiling cooling and floor heating system in TRNSYS showed only minor differences compared to FLUENT within this first analysis. However, further aspects like internal and external loads have to be considered in the future analysis. Once the surface heating and cooling models are validated (or if necessary further developed), control strategies of heat pumps and chillers in combination with thermal storage masses of the floor or ceiling can be analysed via simulation in this Hardware-in-the-Loop test rig.

The communication between LabView and TRNSYS was realized and tested with the simulation of a small office building. With that an absorption cooling machine was modelled with a curve fit in LabView, in order to test the communication with a real simulation case. The next step will be that instead of the cooling machine model a real cooling machine will be measured in LabView, communicating with the TRNSYS simulation model interactively.

Finally, with the help of this Hardware-in-the-loop test rig energy performance of NZEB-concepts can be evaluated.

\section{ACKNOWLEDGEMENT}

The authors want to thank all supporters, the project energy4buildings is funded by the Austrian Ministry for Transport, Innovation and Technology BMVIT and the Austrian Ministry of Economy, Family and Youth BMWFJ within the funding scheme COIN. The project "Test and demonstration rig: thermal cooling" is funded by the European Regional Development Fund and the Government of Burgenland. The investigations were also accomplished by the impulse program "Josef Ressel-Centre" funded by the BMWFJ.

\section{REFERENCES}

[1] Directive 2010/31/EU (2010): Directive of the European Parliament and of the Council on the energy performance of buildings (recast).

[2] Stutterecker, W., Blümel, E. (2012): Energy plus standard in buildings constructed by housing associations?, Energy, Volume 48, Issue 1, December 2012, Pages 56-65, ISSN 0360-5442, 10.1016/j.energy.2012.06.044.

[3] Töglhofer, C., Gobiet, A., Habsburg-Lothringen, C., Heimrath, R., Michlmair, M., Prettenthaler, F., Schranzhofer, H., Streicher, W., Truhetz, H. (2009): Heat.at: Die Auswirkungen des Klimawandels auf Heiz- und Kühlenergiebedarf in Österreich. Österreichische Akademie der Wissenschaften, Wien

[4] Streicher, W., Schnitzer, H., Titz, M., Tatzber, F., Heimrath, R., Wetz, I., et al. (2010): Energieautarkie für Österreich 2050. Endbericht, Innsbruck

[5] Wietschel, M., Arens, M., Dötsch, C., Herkel, S., Krewitt, W., Markewitz, P., et al. (2010): Energietechnologien 2050 - Schwerpunkte für Forschung und Entwicklung. Fraunhofer-Institut für System- und Innovationsforschung, Stuttgart

[6] Thür, A., Vukits, M., Becke, W. (2012): Ein Jahr Feldmessung von fünf Solar-Kombianlagen mit Wärmepumpen. Universität Innsbruck, AEE INTEC, Konferenzband Solar 2012, Gleisdorf

[7] Klein, S.A. et al. (2010): TRNSYS 17 - a TRaNsient System Simulation program. Version 17.01.0028, Solar Energy Laboratory, University of Wisconsin-Madison

[8] National Instruments (2013): LabVIEW Professional Development System, LabVIEW 2013

[9] Fluent, 2012. ANSYS FLUENT 14.5 Theory Guide. ANSYS, Inc. Southpointe, 275 Technology Drive 000285 Canonsburg, PA 15317.

[10] Heschl, C. (2013): Simulation of the ceiling cooling system, internal report, project Josef Ressel-Centre, Fachhochschule Burgenland GmbH, Pinkafeld

[11] Klanatsky, P. (2014): Simulation of the floor heating system, internal report, project eNNOVATION, Forschung Burgenland $\mathrm{GmbH}$, Pinkafeld

[12] ÖNORM EN ISO 7730 (2005). Ergonomics of the thermal environment - Analytical determination and interpretation of thermal comfort using calculation of the PMV and PPD indices and local thermal comfort criteria, Austrian Standards Institute, Vienna

[13] Directive 2012/27/EU (2012): Directive of the European Parliament and of the Council on energy efficiency. 